Results The first output is a research to implementation initiative by a Knowledge Transfer Program on pedestrian safety from Safe Kids Malaysia research output on pedestrian safety. The outcome is an attempt by the school institution to apply to be designated as the First International Safe School in Malaysia within the Safe Communities Framework in 2015. 1178 Children, 70 Teachers, 8 Staffs and 870 parents are using the pedestrian walkway and this has reduced their risk on road by removal of hazard.

Conclusions The dream impact we are exploring for this International Safe School movement leading towards First International Safe Community in Malaysia. We hope this will yield a reduction in traffic crashes and injuries involving child pedestrians in this community.

\section{ACCIDENTAL INJURY PREVENTION IN COMPREHENSIVE SCHOOL IN FINLAND}

Laura Kolehmainen, Kirsi Wiss, Anne Lounamaa, Ulla Korpilahti. National Institute for Health and Welfare, Finland

\subsection{6/injuryprev-2016-042156.939}

Background All pupils participating in education are entitled to a safe learning environment. The Health Care Act (1326/2010) obliges comprehensive schools to monitor health and safety of school environments and well-being in learning communities every three years.

Methods Health and welfare promotion in schools and educational institutions has been monitored by the National Institute for Health and Welfare and the Board of Education since 2006. In 2013 data were collected nationally using a form addressed to headmasters of Finnish comprehensive schools $(\mathrm{N}=2734)$. The response rate was $74 \%(\mathrm{~N}=2022)$. The topics covered also accidental injuries at school, accidental injury prevention, and safety promotion.

Results Inspection of health and safety of school environments and well-being in learning communities provides valuable information about the safety situation in the schools and their surroundings. One in four schools (24\%) reported either that they did not know whether an accidental injury risk assessment indoors had been part of the inspection or that these issues had not been considered in the inspection. About three in four schools (76\%) had taken into account indoors risk locations for accidental injuries.

One in three schools (33\%) did not know whether an accidental injury risk assessment outdoors had been included in the most recent inspection or not. Accidental injury risks had been assessed in 68 per cent of the schools, and outdoors safety was found deficient in 28 per cent of the schools.

Conclusions Multiprofessional inspection provides valuable information about school indoors and outdoors conditions, school surroundings, and safety at school trips. Most schools had paid attention to accidental injury prevention and safety both indoors and outdoors. However, a significant part of the schools did not monitor the risk of accidental injuries indoors or in the school yard.

\section{PILOT MODEL FOR CHILD RESTRAINT USE IN CAR IN THAILAND: A CASE STUDY OF KHON KAEN PROVINCE}

Suwanna Thadapipat, Sukonrutna Chanvirutna . KhoKaen Hospital

10.1136/injuryprev-2016-042156.940
Background Road traffic accidents is the second most common cause of death among Thai children after drowning. There is very little use of child restraint in car in Thailand. Therefore, we were established the promotion of child restraint use among Thai family during postpartum period.

Objectives To explore attitudes,normative beliefs and intention for child restraint used in Thai family

Methods This qualitative study was conducted during November 2014 to April 2015 at Khon Kaen Hospital. The volunteers are 30 Thai parents of postpartum with healthy infant who received healthcare information and use their cars on a daily basis. The process of implementation consists of the practical training in the use of child restraint to volunteer after birth and group meeting every 2 months. Interviewing data were collected at 6 months after training to identify attitudes normative beliefs and intention to use child restraint

Results $90 \%$ of participating parents used the child restraint continuously and correctly. The reasons for using the child restraint were: confidence that their children will be safer than carrying their children on their lap in the car,having more concentration to drive the car, muchmore comfort when the mothers have to drive the car alone. While the intermittent a child restraint used groups, their comments were inappropriate to use child restraint due to the children were hot, crying and refusing, travelling at long distance, no child -parents bonding by the separated car seat, influence on decision by the old age people in families who believed that holding baby by parent were safer than using child restraint. the number of peoples in their families and the size of their car, but soon they found technique to solve the problems and shared the technique among the group.Next steps, we are going to advocate for child restraint legislation, intensive public relation to raise more social awareness for safety of the children in the car.

Conclusions Participation of knowledge exchange in child restraint use in the car among participants can lead to improve and support good cognitive behaviour in the subgroup. However supporting the devices with low price, strong public relation, education program for mothers at ANC and well baby clinics and legislation are important factors that influence behavioural change.

\section{PREVENTING CHILDHOOD INJURIES THROUGH EDUCATIONAL POSTERS}

P Mtambeka , N du Toit , D Schulman, AB van As. Childsafe South Africa, Red Cross War Memorial Children's Hospital

\subsection{6/injuryprev-2016-042156.941}

Background Since 1991, Childsafe South Africa has gathered available statistics on childhood injuries and deaths presenting at Red Cross War Memorial Children's Hospital Trauma Unit in Cape Town, South Africa. This database serves as a surveillance system on childhood injuries and it is considered to be one of the biggest paediatric injury databases. The database has been systematically analysed for a large number of clinical and epidemiological studies as they relate to childhood injuries.

Childsafe South Africa collaborated with relevant stakeholders and developed educational posters that convey universal safety information and recommendations for families, crèches, and care givers, based on the statistics from the database.

Methods A series of three educational posters (1) "Growing Safely" (2008), (2) “Living Safely" (2010), and (3) “Travelling 
Safely" (2011) were developed encompassing the various characteristics of children throughout their development and providing corresponding harm reduction principles.

These posters identify the early developmental limitations of the children; recognise typical injuries within specified age groups (from the database); illustrate the best practice scenario and best prevention are organised by age and are coloured with detailed pictures of accident precautions and suggestions.

Results "Growing Safely" is an international award winning poster and depicts the child from birth until age six. It raises crucial awareness by providing safety recommendations, by age, for fall prevention, drowning risks, car safety, and the dangers of common household items.

The "Living Safely" poster was designed in response to a growing number of hot water burns and flame burns. Thus, "Living Safely" is formatted in the same award winning design and addresses burn risks and fire safety. The topics portrayed in "Living Safely" include; sunburn protection, hot water burn prevention, electrical cord/outlet recommendations, and proper fire extinguishing directions.

The most recently developed poster, "Travelling Safely" illustrates age appropriate vehicle restraints, helmet and safety guard suggestions, street crossing advisory, and tips for proper bicycling. To provide such imperative information, the three posters have been translated into local languages.

Conclusion The Childsafe South Africa posters have been well received and regarded as best educational tool not only in South Africa but around the world. People are able to connect with messages as it's extracted from simple situations that take place on daily basis. Images of real people (children) are being used and the pictorial depictions overcome literacy levels.

\section{WALK SAFE CAMPAIGN: A RAIL-ROAD COMMUTERS' SAFETY PROGRAM WITH RAILWAYS (SINCE 2012 AND CONTINUED)}

${ }^{1}$ Rajni Gandhi. Trax Sports Society, Member of Global Alliance of NGOs for Road Safety, International Road Federation (INDIA Chapter)

\subsection{6/injuryprev-2016-042156.942}

Background The 'High Level Safety Review Committee' (appointed by Railway Ministry, Government of India) report2012 states that the estimation is almost 15000 persons get killed in on the entire railway system every year. During 2007-08 to October, 2011, 1600 Railway Staff was killed and another 8700 people were injured due to railway accidents. It is to be noted that casualties in train accidents include a large chunk of deaths and injuries due to unmanned level crossing accidents attributed to the negligence of road users.

Methods With the objective to sensitise daily Railway commuters about developing good Safety Habits as Railway Commuters and Road Users, we devised a Specialised/Trained team. This team conducts Workshops, Performs Street Plays and Distributes Educational Pamphlets and interacts with target group members. Under this campaign we have covered different sections falling under different divisions of Northern and North-Central Railways.

Target Locations - Schools, Colleges, Traffic Intersections, Railway Platforms, Unmanned Railway Crossings

Area Covered - Urban and Rural

States Covered - Haryana, Uttar Pradesh, Punjab, Rajasthan and Delhi

Results This is an ongoing operation the impact of such campaigns need to be evaluated over a readably period. However, on the spot response has been encouraging and positive.

Conclusions The existing campaign has been planned for Northern and Northern Central Division. We plan to take it further to other divisions of Railways in coming years. It is expected that the $50 \%$ of the entire Railways network would be covered in the next five years.

\section{RISK FACTORS PREDISPOSING TO ROAD TRAFFIC INJURY IN YOUNGSTERS: A CASE-CONTROL STUDY}

${ }^{1,2}$ Mohamed Mouloud Haddak. 'University of Lyon, France; ${ }^{2}$ Ifsttar-Umrestte, France

\subsection{6/injuryprev-2016-042156.943}

Background Youngster injury is the leading cause of mortality, morbidity and permanent disability in adolescent in the developed world. The objective of this research is to study the joint effect of family and contextual socioeconomic characteristics of teenagers on their risk of road accidents, taking into account their mobility practices, their behaviour and their attitude to risk.

Methods A case-control study was conducted on a population of 601 young people aged 14-17, in 2013. Cases (208 subjects) were selected from the Rhône Road Trauma Registry. Controls (393 subjects) adjusted by age and sex were randomly selected by telephone. L'exposition à la circulation routière est mesurée pour chaque mode de transport utilisé par le budget-temps. The relationships between SES status, urban/periurban-rural location, mode of transport, mobility practice, and injury type were determined using conditional logistic regression. Exposure to road traffic is measured for each mode of transportation used by the weekly time budget.

Results The intensive use of motorised two-wheelers holds an essential role in the risk of road accidents between 14 and 17 years $(\mathrm{OR}=4.1[2.3-7.2])$, followed by regular cycling $(\mathrm{OR}=3.6[2.0-6.5])$ and skating $(\mathrm{OR}=1.9$ [1.1-3.1]). Socioeconomic status of young people is highlighted: students in professional college or young apprentices are at higher risk $(\mathrm{OR}=2.1[1-4.3])$. Compared with urban adolescents, adolescents living in rural areas suffer a 1.9 higher risk (1.9 [1.2-3.0]). The links between road risk behaviour and smoking are also underlined (OR $=4.4$ [2-9.7]).

Conclusions These results show that adolescent road traffic injury in Rhône is a major health concern, especially among motorcyclist males (40\% of the injuries) from rural area and from lower SES. But this study also shows the significant impact of behavioural factors (tobacco, cannabis) on the risk of accident. 